\title{
Effect on prostatic specific antigen by a short time treatment with a Curcuma extract: A real life experience and implications for prostate biopsy
}

\author{
Andrea Fabiani ${ }^{1}$, Carolina Morosetti ${ }^{2}$, Alessandra Filosa ${ }^{3}$, Emanuele Principi ${ }^{4}$, Luca Lepri ${ }^{1}$, \\ Valentina Maurelli ${ }^{1}$, Fabrizio Fioretti ${ }^{1}$, Lucilla Servi $^{1}$ \\ ${ }^{1}$ Unit of Urology, Surgical Department, Macerata Hospital, Area Vasta 3, ASUR Marche, Italy; \\ ${ }^{2}$ Clinical Pathology, Jesi (AN), Italy; \\ ${ }^{3}$ Section of Pathological Anatomy, Department of Clinical Pathology, Macerata Hospital, Area Vasta 3, ASUR Marche, Italy; \\ ${ }^{4}$ Resident, Urologic Clinic, Politechnic University of Marche Region, Ancona, Italy.
}

\begin{abstract}
Summary Introduction and objectives: PSA elevation is associated with prostate cancer and it is used in screening programs for its diagnosis. It is one of the most common indications for referral to an urologist. There's no consensus about what to do in PSA elevation management. Antibiotics, nutraceuticals or anti-inflammatories are commonly prescribed in daily practice. Our objective was to verify the effect on the PSA value of a short 30-day trial of a curcuma extract, than to discuss the implications in terms of reducing the number of prostate biopsies performed.

Patients and methods: We enrolled 50 consecutive patients admitted at our attention for a first PSA over the level of 4 $\mathrm{ng} / \mathrm{ml}$ or for a suspected PSA rising defined as PSA velocity $(P S A v)>0.75 \mathrm{ng} / \mathrm{ml} /$ years. They received treatment with curcuma extract, 2 tablets per day for 30 day. All patients received a second PSA measurement and TRUS within 6 days from the end of the therapy. In case of PSA reduction below $4 \mathrm{ng} / \mathrm{ml}$, patients were reassured and invited to repeat a PSA control over the time. When PSA level were persistently high over 4 $\mathrm{ng} / \mathrm{ml}$ or in case of any rising, patients underwent a transrectal ultrasound guided 12-core prostatic biopsy (TRUSbx).

Results: Mean age of the patients was $64.56 \pm 8.88$ (range, 4281 years). Prostate volume was $48.34 \pm 15,77 \mathrm{ml}$ (range, 18-80 $\mathrm{ml}$ ). At visit $1, P S A$ value was in mean $6,84 \pm 3.79 \mathrm{ng} / \mathrm{ml}$ (range 2.93-21ng/ml). Consequently, mean PSA density value was $0.16 \pm 0.16$ (range 0.05-1.11). PSA free and PSA total ratio at baseline was $16.85 \pm 3.9 \%$ (range $8-26 \%$ ). At visit 2 , the prostate volume did not change. Total PSA was $4.65 \pm 2,67$ $\mathrm{ng} / \mathrm{ml}$ (range 1-16.82 $\mathrm{ng} / \mathrm{ml}$ ). PSA free and PSA total ratio (PSAF/T) after treatment was $19.68 \pm 5.35 \%$ (range 7.8-29\%). The differences of total PSA and PSAF/T between visit 1 and visit 2 were $<0.0001$ and $p<0.0036$, respectively. We performed 26 TRUSbx. Prostate cancer was diagnosed in 6 cases, PIN HG in 2 cases and non neoplastic findings in the remnants 18 patients.

Conclusions: Use of the Curcuma extract is able to lower the PSA value after a 30-day intake period. We are not able to state that the reduction of PSA after intake of this Curcuma extract may exclude a prostate cancer. We need further studies to evaluate that.
\end{abstract}

KEY wORDS: Prostatic specific antigen; Curcuma; Prostate biopsy; Prostate cancer; Nutraceuticals.

Submitted 31 December 2017; Accepted 12 March 2018

\section{INTRODUCTION}

Prostatic specific antigen (PSA) may be raised as a result of prostate cancer, benign prostatic hyperplasia, prostatic infection or inflammation (1). A raised PSA, over a value considered as normal (i.e. $4 \mathrm{ng} / \mathrm{ml}$ ), usually prompts an ultrasound guided prostate biopsy (TRUSbx) even in absence of an abnormal digital rectal examination (DRE). TRUSbx is a procedure performed in an ambulatory setting but it is characterized by a morbidity and a patient's discomfort (2). The scientific literature does not define with certainty what should be the attitude to be taken by the urologist when he is managing a PSA elevation, without symptoms and without anomalous findings to the DRE. Although the prescription of antibiotics or nutraceuticals or anti-inflammatories is widespread in daily practice, the guidelines recommend repeating PSA over time, but this does not protect against performing biopsies with negative results for neoplasia.

Our objective was to verify the effect on the PSA value of a short 30-day trial of a Curcuma extract and if this effect could have an implication in terms of reducing the number of prostate biopsies.

\section{Patients AND MEthods}

\section{Patients and study design}

This was a prospective mono-institutional real-life study of 50 patients who were admitted at our attention for a first PSA raised over the level of $4 \mathrm{ng} / \mathrm{ml}$ or for a suspected PSA rising defined as PSA velocity (PSAv) $>0.75$ $\mathrm{ng} / \mathrm{ml} /$ years. The exclusions criteria were any previous surgical prostatic treatment, any prior prostate biopsy, any therapy with 5-alpha-reductase inhibitors (5ARI); (finasteride or dutasteride), any abnormalities detected at DRE, any alterations in transrectal ultrasound prostate study (TRUS), any low urinary tract symptoms (LUTS) suggesting for urinary tract infection (UTI) or recognized physiologic or iatrogenic cause of PSA rising.

Patients enrolled received treatment with PROSTAFLOG ${ }^{\circledR}$, 2 tablets per day for 30 day. They received a second PSA 
measurement and TRUS within 6 days from the end of the therapy. In case of PSA reduction below $4 \mathrm{ng} / \mathrm{ml}$, patients were reassured and invited to repeat a PSA control over the time. When PSA level were persistently high over $4 \mathrm{ng} / \mathrm{ml}$ or in case of any rising, patients underwent a transrectal ultrasound guided 12-core prostatic biopsy (TRUSbx).

\section{Technical aspect and measurements}

At first line visit, patients in each group underwent a clinical evaluation with a DRE and TRUS (end fire BK Medical probe, 8808). Prostate volume (ml) was measured according to the prostatic ellipsoid formula, multiplying the largest anteroposterior, transverse and cephalocaudal prostate diameters by 0.524 . PSA density (PSAD) $(\mathrm{ng} / \mathrm{ml} / \mathrm{g})$ was defined as PSA $(\mathrm{ng} / \mathrm{ml})$ at the enrolling visit time divided by prostate volume (ml). TRUS guided prostate biopsy was performed by a single experienced urologist and consisted in 12 cores of tissue targeting the peripheral zone at the apex, mid gland and the base on each side of the gland, whit an end fire needle access route. Prostatic cores were evaluated by a single dedicated genitourinary pathologist.

\section{Herbal product}

PROSTAFLOG ${ }^{\circledR}$ (Naturmed srl) is a food supplement based on plant extracts of Curcuma, Boswellia, Nettle and Maritime Pine, which promote the physiological functions of the prostate. Component quantitative are, per dose (2 tablets): Curcumin $500 \mathrm{mg}$, Boswellia $300 \mathrm{mg}$, Nettle $240 \mathrm{mg}$ (Betasitosterol intake $1 \mathrm{mg}$ ), Maritime Pine $200 \mathrm{mg}$ (Betasitosterol intake $150 \mathrm{mg}$ ), Soy's Lecitine $70 \mathrm{mg}$.

\section{Statistical analyses}

The statistical analysis was performed with Med Calc ver. 9.0.2.1 demo mode.

For quantitative parameters were determined: mean, standard deviation, median. For all quantitative parameters, the normality or less of the distribution was preliminarily verified with D'AgostinoPearson test. If the normality was accepted, the data analysis was performed with parametric tests. Otherwise with non-parametric tests.

\section{Results}

As showed in Table 1, mean age of the patients was $64.56 \pm 8.88$ (range, $42-81$ years). Prostate volume was $48.34 \pm 15.77 \mathrm{ml}$ (range, $18-80 \mathrm{ml}$ ). At visit 1 , PSA value was in mean $6.84 \pm 3.79 \mathrm{ng} / \mathrm{ml}$ (range, $2.93-21 \mathrm{ng} / \mathrm{ml}$ ).

Consequently, mean PSA density value was $0.16 \pm 0.16$ (range 0.05-1.11)

PSA free and PSA total ratio at baseline was $16.85 \pm 3.9 \%$ (range,

Table 2.

Table 3.
8-26\%). At visit 2, the prostate volume did not change. Total PSA was $4.65 \pm 2.67 \mathrm{ng} / \mathrm{ml}$ (range, $1-16.82 \mathrm{ng} / \mathrm{ml}$ ). PSA free and PSA total ratio (PSAF/T) after treatment was $19.68 \pm 5.35 \%$ (range, $7.8-29 \%$ ).

The differences of total PSA and PSAF/T between visit 1 and visit 2 were calculated. Given the non-normal distribution of data, the analysis was performed with Wilcoxon tests for paired data.

The value of $\mathrm{p}$ was $<0.0001$ for total PSA. For PSAF/T, $p<0.0036$. The differences, therefore, between "before and after" were statistically significant. The power of the test was equal to 0.979 (used software $G^{*}$ Power 3.0.10). Total PSA reduction was observed in 41 cases ( $82 \%)$. Of 50 patients, $26(52 \%)$ underwent TRUSbx because of persistent total PSA elevation $(9 / 50,18 \%)$ or PSA reduction but not under the cut off value of $4 \mathrm{ng} / \mathrm{ml}(17 / 50$, $34 \%)$. Hystopathologic results showed prostatic adenocarcinoma in 6 cases $(6 / 26,23 \%)$, in $10(10 / 26,38.5 \%)$ acute and chronic flogosis, in 8 (8/26, 30.8\%) atrophic findings. Monofocal PIN HG was detected in $7.69 \%$ (2/26). Gleason score was $3+3$ in $67 \%(4 / 6), 4+4$ in $17 \%$ (1/6). In case of positivity for prostatic cancer, PSA was

Table 1.

Patients characteristics at visit 1 and visit 2

\begin{tabular}{|lccc}
\hline & Visit 1 & Visit 2 & $\mathbf{P}(<\mathbf{0 . 0 0 5 )}$ \\
\hline Age (mean, years) & 64.56 & - & - \\
\hline PSA (mean, ng/ml) & 6.84 & 4.65 & $<0.0001$ \\
\hline PSA F/T (mean, \%) & 16.8 & 19.68 & $<0.0036$ \\
\hline Prostate volume (mean, ml) & 48.34 & - & - \\
\hline PSA D & 0.16 & - & - \\
\hline
\end{tabular}

Patient's characteristics according to the PSA value after trial *.

\begin{tabular}{|lccc}
\hline & $\begin{array}{c}\text { Patients with PSA } \\
\text { lowered under 4 } \mathbf{~ g / m l} \\
\text { (n. 24) }\end{array}$ & $\begin{array}{c}\text { Patients withwith PSA } \\
\text { lowered still over 4 ng/ml } \\
\text { (n. 17) }\end{array}$ & $\begin{array}{c}\text { Patientswith PSA } \\
\text { augmentation } \\
\text { (n. 9) }\end{array}$ \\
\hline Mean age (years) & 63.4 & 65.29 & 66.2 \\
\hline Mean PSA variation $(\mathrm{ng} / \mathrm{ml})$ & 2.91 & 2.71 & 0.70 \\
\hline Mean prostatic volume $(\mathrm{ml})$ & 46.62 & 53.17 & 43.7 \\
\hline Number positive biopsies & - & 1 & 5 \\
\hline Number negative biopsies & - & 16 & 4 \\
\hline * Not statistically significant differences were found. & & \\
\hline
\end{tabular}

Patient's characteristics according to the prostatic biopsies results.

\begin{tabular}{|c|c|c|c|}
\hline & Biopsy positive for cancer & Biopsy negative for cancer & Biopsy not performed \\
\hline Number of patients & 6 & 20 & 24 \\
\hline Mean PSA (ng/ml) & 6.48 & 6.19 & 2.89 \\
\hline Mean PSA D & 0.14 & 0.17 & 0.16 \\
\hline Mean PSA F/T (\%) & 13.8 & 20.35 & 20.75 \\
\hline Mean PSA variation (ng/ml) & $0.664 *$ & $2.43 * *$ & 2.91 \\
\hline \multicolumn{4}{|c|}{$\begin{array}{l}\text { * Mean value calculated on } 5 \text { cases with PSA progression; in one case, } \\
\text { PSA total has been lowered by trial }(0.5 \mathrm{ng} / \mathrm{ml}) \\
\text { ** All variation were negative. }\end{array}$} \\
\hline
\end{tabular}


in elevation in 5 cases out of 6 . Only in one positive case, despite the total PSA reduction of $0.5 \mathrm{ng} / \mathrm{ml}$ (from 9 $\mathrm{ng} / \mathrm{ml}$ to $8,5 \mathrm{ng} / \mathrm{ml}$ ), we have diagnosed an adenocarcinoma. This could mean that in 16 case of 17 (94\%) who underwent TRUSbx for PSA not sufficiently reduced, TRUSbx could not be performed based on the finding of PSA reduction after the trial with curcuma extract.

The mean of reduction was $2,94 \mathrm{ng} / \mathrm{ml}$ (range $0.26-16.2$ $\mathrm{ng} / \mathrm{ml})$. The $44.5 \%(4 / 9)$ of patients in whom PSA increased despite the extract intake had a neoplastic biopsy outcome, but in 2/9 biopsy findings was a PIN hg. Thus, the $67 \%$ of these (6/9) with a PSA elevation after the trial, had a non benign biopsy result.

In Table 2 and Table 3 we reported mean PSA values according to results after trial and biopsies findings (negative or positive for neoplasm). All subjects included in the evaluation tolerated treatments with Curcuma extract. No major complications were registered in case of ultrasound guided prostate biopsy.

\section{Discussion}

A raised PSA is one of the most common indications for referral to an urologist. However, before a PSA test is undertaken, it is important that a frank and honest discussion should be had with the patient about the pros and cons of this blood test (3). In effect, PSA measurement has marked a new era in the diagnosis of prostate cancer (4). This antigen, produced almost exclusively by the epithelial cells of the prostate, is not a cancer specific but an organ-specific marker (5). Therefore, its serum levels may increase in non malignant conditions such as benign prostate hypertrophy, prostatic infection or inflammation, and prostate cancer (1). The histological architecture of the prostate is disturbed in both prostate cancer and prostatitis, causing greater PSA leakage from the lumen of the prostatic glands into the circulation, increasing PSA levels (6). Because elevated serum PSA is associated with prostate cancer and is used in screening programs for prostate cancer, patients with benign causes for elevation of serum PSA present a challenge, especially when clinical evaluation and DRE are unremarkable. Twenty-five percent of men with PSA levels from 4 to $10 \mathrm{ng} / \mathrm{ml}$ have a biopsy-proven prostate cancer, but $75 \%$ undergo unnecessary prostate biopsies, potentially leading to anxiety, discomfort and significant additional health care cost (7). In men with an increasing PSA without clinical evidence of infection, a common rational is to treat a subclinical prostate infection, in order to reduce the PSA value, avoiding unnecessary prostate biopsies (8). Several years ago, already, Scardino criticized the unjustified use of antibiotics in a group of patients with a PSA elevation and no symptoms due to an UTI. He emphasized the various inherent disadvantages associated with this approach, such as costs, toxicity, and the promotion of resistant bacterial species development that would have exposed the biopsied patient to more resistant and aggressive sepsis (9). Also in 2014, Fandella et al., showed no advantages due to an empiric antibiotic therapy (full dose fluoroquinolone for 20 days) to reduce PSA values and avoid unnecessary biopsy in patients with PSA levels between 4-10 ng/mL and no signs or symptoms of infections. They concluded that empiric use doesn't seem to be of clinical benefit in absence of a clinical or laboratory evidence of infection and it might paradoxically be harmful. In their opinion, the repetition of a PSA test before scheduling a biopsy remains the only acceptable approach (10). However, over the years, we have witnessed the presentation of various therapeutic approaches aimed at the intervention on the increase of PSA before resorting to a biopsy. Even the current increased recourse to multiparametric Magnetic Resonance Imaging (mpMRI) presents some aspects of accuracy and costs that make it impracticable in a first level of investigation (11-12). Bozzini et al. recently reported their multicentric observational experience with beclomethasone dipropionate (BDP) rectal suppositories in case of nonbacterial prostatitis. The eightyfour percent of the patients enrolled underwent a 20-day course of therapy with BDP suppositories and Serenoa Repens (Saw palmetto, dose of $320 \mathrm{mg}$ per day).

Results showed an effect on symptoms related to prostatitis, but not on PSA levels. Authors declared that, as expected, PSA levels remained stable since it is not a specific parameter for lower urinary tract inflammation (13). But, we know from the literature that inflammation of the prostate is an histological finding in almost every set of prostate biopsies, even when there are no signs of clinical prostatitis. As observed in our study population, this subclinical inflammation can cause PSA elevation. Furthermore, not the extent of inflammation is of importance, but the disruption of epithelial integrity caused by the inflammatory infiltrate. When confronted with a patient with an elevated PSA level whose prostate biopsies reveal no malignancy but only inflammation, this concept can help in determining the need for quick repeat biopsies (14). Instead, a PSA assessment is more and more frequently prescribed also by general practitioners before being sent to the specialist. Hence, the increasing interest in and use of complementary and alternative therapies (CAM), especially nutraceuticals (15). In Italy, $50 \%$ of the medications used for benign prostatic hyperplasia are phytotherapies, and in Germany and other European countries, phytotherapies are first-line treatment for mild to-moderate benign prostatic hyperplasia (BPH)/LUTS (16). The best-studied CAM therapies for prostate disease include dietary modification, the aforementioned Serenoa repens (Saw palmetto), Pygeum africanum, phytosterols, rye pollen extract and others, and vitamins and minerals, such as vitamin $\mathrm{E}$ and selenium $(17-20)$. These products may be utilized alone or in association with antibiotics $(21,22)$ or anti-inflammatory drugs (23) exploiting in particular the rational of Serenoa's anti-inflammatory action (24). Nevertheless, many of the studies are small, short, not randomized, and/or not placebo controlled and they are not focused on the effects on the PSA. We have focused our study on curcuma for the growing attention that literature is addressing to this substance, given its proven effects on PSA (25-26) and the interest of research on the possible use in the treatment of symptomatic prostatitis (27). In particular, we wanted to evaluate the possibility of obtaining an effect on PSA in just a few weeks so as to reduce the patient's stress and reassure him about the 
need to deal with a diagnosis of cancer (28). The results obtained allowed us to verify how curcuma extract is able to lower PSA. Among the biopsies performed, we observed that the positive ones show a PSA increasing or however a less marked reduction compared to patients with negative biopsy. As regards the analysis of the data, taking into account the number of biopsies carried out in patients treated with curcuma extract, it can of course be said that the treatment with this curcuma extract has greatly reduced the number of biopsies to be performed, with 26 biopsies performed respect the 50 that would have been made on the basis of the value of the initial PSA, with a reduction of biopsy performed of $48 \%$.

We are certainly not able to state that the reduction of PSA after intake of curcuma extract, in case of PSA > 4 $\mathrm{ng} / \mathrm{ml}$ and negative DRE, can be used as "ex adiuvantibus criterion" for not perform unnecessary biopsy. However, considering the verified statistical power of the results obtained in our cohort, it is undeniable that this curcuma extract is able to lower the value of PSA.

In particular, when PSA raise after trial, biopsy results are not benign in $67 \%$ of cases. We recognize that our study suffer from several limitations. First. The lack of a control group. In order to define the role of curcuma extract in reducing unnecessary biopsy, we should make a comparison with a placebo control group. Second, to confirm our preliminary real life experience, concerning the rapid and significant reduction of PSA, this curcuma extract must be employed in a more sized patient's sample. Third. Not all 50 patients enrolled were biopsied. It should be recognized that the execution of the biopsy with a reduced PSA, after rising, would have been outside the current indications (2).

\section{Conclusions}

PSA rising is one of the most common indications for urological evaluation. Because elevated serum PSA is associated with prostate cancer and is used in screening programs, patients with benign causes for elevation of serum PSA present a challenge, especially when clinical evaluation and DRE are unremarkable. Use of curcuma extract is able to lower the value of PSA. We are not able to state that the reduction of PSA after trial may exclude a prostate cancer. We need further studies to evaluate that. It is desirable that the use of nutraceutical products in the treatment of prostatic pathology is correctly evaluated in appropriate studies so that, in particular, the use of curcuma does not remain a non-evidence-based practice.

\section{AUtHORS' CONTRIBUTIONS}

All Authors participated in the design and conduct of the study. All Authors reviewed and approved the final version of the manuscript.

\section{REFERENCES}

1. Tchetgen MB, Oesterling JE. The effect of prostatitis, urinary retention, ejaculation and ambulation on the serum prostate-specific antigen concentration. Urol Clin North Am. 1997; 24:283-291.
2. Fandella A, Scattoni V, Galosi A. Italian Prostate Biopsies Group: 2016 Updated Guidelines Insights. Anticancer Res 2017; 37:413424.

3. Kirby RS. Raised Prostate-Specific Antigen. In Gontero P, et al. (Eds.) Problem Based Urology. chapter 24, Springer-Verlag London 2013; pp 185-189.

4. Stamey TA, Yang N, Hay AR, et al. Prostate-specific antigen as a serum marker for adenocarcinoma of the prostate. N Engl J Med. 1987; 317:909-916.

5. Mottet N, Bastian PJ, Bellmunt J, et al. Guidelines on prostate cancer. In: European association of urology guidelines. European Association of Urology 2014; p. 16

6. Ornstein DK, Smith DS, Rao GS, et al. Biological variation of total, free and percent free serum prostate specific antigen levels in screening volunteers. J Urol. 1997; 157:2179-2182.

7. Catalona WJ, Smith DS, Ratliff TL, et al. measurement of prostate-specific antigen in serum as a screening test for prostate cancer. N Engl J Med. 1991; 324:1156-1161.

8. Lorente JA, Arango O, Bielsa O, et al. Effect of antibiotic treatment on serum PSA and percent free PSA levels in patients with biochemical criteria for prostate biopsy and previous lower urinary tract infections. Int J Biol Markers. 2002; 17:84-89.

9. Scardino PT. The responsible use of antibiotics for an elevated PSA level. Nat Clin Pract Urol. 2007; 4:1.

10. Fandella A, Benvenuto S, Guidoni E, et al. Empiric antibiotics therapy for mildly elevated prostate specific antigen: Helpful to avoid unnecessary biopsies? Arch Ital Urol Androl. 2014; 86:202204

11. Ahmed HU, Bosaily AES, Brown LC, et al. Diagnostic accuracy of multi-parametric MRI and TRUS biopsy in prostate cancer (PROMIS): a paired validating confirmatory study. Lancet 2017; 389:815-822.

12. Faria R, Soares MO, Spackman E, et al. Optimising the diagnosis of prostate cancer in the era of multiparametric magnetic resonance imaging: a cost effectiveness analysis based on the prostate MR imaging study (PROMIS). Eur Urol. 2018; 73:23-30.

13. Bozzini G, Provenzano M, Buffi N, et al. An observational study of the use of beclomethasone dipropionate suppositories in the treatment of lower urinary tract inflammation in men. BMC Urology; 2016; 16:25-32.

14. Schatteman PH, Hoekx L, Wyndaele JJ, et al. Inflammation in prostate biopsies of men without prostatic malignancy or clinical prostatitis: correlation with total serum PSA and PSA density. Eur Urol. 2000; 37:404-412

15. Curtis NJ, Shoskes D, Roehrborn GC, et al. Nutraceuticals in prostate disease: The Urologist role. Reviews in Urology. 2010; 10:192-206.

16. Dreikorn K. Complementary and alternative medicine in urology. BJU Int. 2005; 96:1177-84.

17. Morgia G, Cimino S, Favilla V, et al. Effects of serenoa repens, selenium and lycopene (Profluss) on chronic inflammation associated with benign prostatic hyperplasia: results of "FLOG" (Flogosis and Profluss in prostatic and Genital Disease), a multicentre Italian study. Int Braz J Urol. 2013; 39:214-221.

18. Suardi N, Gandaglia G, Nini A, et al. Effects of Difaprost on voiding dysfunction, hystology and inflammation markers in patients with benign prostatic hyperplasia who are candidates for surgical treatment. Minerva Urol Nefrol. 2014; 66:119-125. 
19. Tiscione D, Gallelli L, Tamanini I, et al. Daidzein plus isolase associated with zinc improves clinical symptoms and quality of life in patients with LUTS due to benign prostatic hyperplasia: Results from a phase I-II study. Arch Ital Urol Androl. 2017; 89:12-16.

20. Pirola GM, Puliatti S, Bocchialini T, et al. Efficacy of pollen extract in association with group B vitamins for pain relief in chronic prostatitis/chronic pelvic pain syndrome: A survey of urologists knowledge about its clinical application. Arch Ital Urol Androl. 2017; 89:22-25.

21. Magri V, Trinchieri A, Montanari E, et al. Reduction of PSA values by combination pharmacological therapy in patients with chronic prostatitis: implications for prostate cancer detection. Arch Ital Urol Androl. 2007; 79:84-92.

22. Cai T, Tiscione D, Gallelli L, et al. Serenoa repens associated with selenium and lycopene extract and bromelain and methylsulfonylmethane extract are able to improve the efficacy of levofloxacin in chronic bacterial prostatitis patients. Arch Ital Urol Androl. 2016; 88:177-182.

23. Gallo L. The Effect of a Pure Anti-inflammatory Therapy on
Reducing Prostate-specific Antigen Levels in Patients Diagnosed With a Histologic Prostatitis. Urology. 2016; 94:198-203.

24. Saidi S, Stavridis S, Stankov O, et al. Effects of Serenoa repens Alcohol Extract on Benign Prostate Hyperplasia. Pril (Makedon Akad Nauk Umet Odd Med Nauki. 2017; 38:123-129.

25. Gupta SC, Patchva S, Aggarwal BB. Therapeutic roles of curcumin: lessons learned from clinical trials. AAPS J. 2013; 15:195218.

26. Ide H, Tokiwa S, Sakamaki K, et al. Combined inhibitory effects of soy isoflavones and curcumin on the production of prostate-specific antigen. Prostate. 2010; 70:1127-1133.

27. Morgia G, Russo IG, Urzi D, et al. A phase II, randomized, single blinded, placebo-controlled clinical trial on the efficacy of Curcumina and Calendula suppositories for the treatment of patients with chronic prostatitis/chronic pelvic pain syndrome type III. Arch Ital Urol Androl. 2017; 89:110-113.

28. Evans R, Edwards AGK, Elwyn G. 'It's a maybe test': men's experiences of prostate specific antigen testing in primary care. Brit J Gen Pract. 2007; 57:303-310

\section{Correspondence}

Andrea Fabiani, MD (Corresponding Author)

andreadoc1@libero.it

Luca Lepri, MD

lucalepri3@libero.it

Valentina Maurelli, MD

valentinamaurelli@hotmail.it

Fabrizio Fioretti, $M D, P h D$

fa.fioretti@libero.it

Lucilla Servi, MD

lucilla.servi@sanita.marche.it

Surgery Department, Urology Unit, Macerata Hospital, ASUR Marche Area Vasta 3, Macerata, Italy

Carolina Morosetti, MD

carolina.morosetti@gmail.com

Clinical Pathology, Jesi, Italy

Alessandra Filosa, MD PhD

alessandrafilosa@yahoo.it

Section of Pathological Anatomy, Department of Clinical Pathology

Macerata Hospital, ASUR Marche Area Vasta 3, Macerata, Italy

Emanuele Principi, MD

principie@gmail.com

Resident, Urologic Clinic, Politechnic University of Marche Region,

Ancona, Italy 